\title{
Ultrastructural characteristics of the spermatozoa of Scelionidae (Hymenoptera, Platygastroidea) with phylogenetic considerations
}

\author{
José Lino-Neto \& Heidi Dolder
}

Accepted: 26 September 2000

\begin{abstract}
Lino-Neto, J. \& Dolder, H. (2001). Ultrastructural characteristics of the spermatozoa of Scelionidae (Hymenoptera; Platygastroidea) with phylogenetic considerations. - Zoologica Scripta, 30, 89-96.

The Scelionidae sperm are distinguished from those of all hymenopterans already studied at least by the presence of a single mitochondrial derivative and the absence of a centriolar adjunct. The absence of an acrosome, in Telenomus podisi, is also unique. The helical nucleus and mitochondrial derivative spiralling around a twisted axoneme can be considered as synapomorphies shared with the Chalcidoidea, and the mitochondrial derivative running together with the nucleus for a long distance can be considered as a synapomorphy shared with the Diapriidae. Therefore, from a consideration of these features, it is possible to suppose that the Scelionidae, Chalcidoidea and Diapriidae are more closely related between themselves than are any of them to the Cynipoidea, since the latter does not share any of the abovementioned features. This supposition agrees with phylogenetic analyses that supported the inclusion of Platygastroidea (Scelionidae and Platygastridae) and Chalcidoidea within the Proctotrupomorpha lineage, as well as the close relationship of these to the Diapriidae, and the exclusion of the Cynipoidea from this lineage.

Fosé Lino-Neto, Departamento de Biologia Geral, Universidade Federal de Viçosa, 36571-000, Viçosa $M G$, Brazil.E-mail: linoneto@unicamp.br

Heidi Dolder, Departamento de Biologia Celular, Universidade Estadual de Campinas, 13083-970, Campinas SP, Brazil.E-mail: heidi@unicamp.br
\end{abstract}

\section{Introduction}

The Hymenoptera, with slightly more than 115000 species described (Gauld \& Hanson 1995), comprises one of the four largest and most biologically diverse order of insects (Gaston 1991). Apart from Isoptera, eusocial behaviour is present only in the Hymenoptera. In this order, there are groups (bees and wasps) which exhibit all gradations of social organization, from solitary to advanced eusocial. In addition, the Hymenoptera contain some very serious pest species, such as the leafcutting ants. This order also contains the single most important group of plant pollinators, the bees, and the most important group of biological control agents for insect pests, the parasitic wasps (Hanson 1995). In spite of the unquestionable economic and ecological importance of the Hymenoptera, there are still many controversies about the evolutionary relationships of this order of insects (Gauld \& Bolton 1988; Rasnitsyn 1988; Dowton \& Austin 1994; Dowton et al. 1997; Ronquist et al. 1999).

The family Scelionidae has been traditionally included in the Proctotrupoidea (Königsmann 1978; Gauld \& Hanson
1995), a paraphyletic superfamily which was a catch-all group for small non-chalcidoid Apocrita not readily assignable to other taxa (Masner 1995). According to Dowton et al. (1997), the phylogeny of the Proctotrupoidea is perhaps least understood within the Apocrita. Probably for these reasons, its families have been grouped in several ways (see Gauld \& Hanson 1995; Dowton et al. 1997). However, Masner (1993) places Scelionidae and Platygastridae in a superfamily, the Platygastroidea, separate from other proctotrupoids, in spite of believing that a thorough phylogenetic analysis, supported by an in-depth morphological study, would be necessary to justify the superfamily and to recognize it properly. Although there is uniformity of opinion about the very close relationship between these two families, some researchers consider this separation somewhat artificial (Gauld \& Hanson 1995).

Spermatozoal ultrastructure has been widely used in taxonomic and phylogenetic studies of various animal groups, including the insects (see Baccetti 1972; Dallai 1979; Dallai \& Afzelius 1990, 1995; Carcupino et al. 1995; Jamieson et al. 
1999). In Hymenoptera, the spermatozoa present sufficient ultrastructural diversity to furnish a character system (Quicke et al. 1992; Lino-Neto et al. 1999, 2000a,b). This system, associated with other character systems, certainly may be used as a basis for phylogeny, to resolve several uncertainties about relationships at different levels, possibly from genera to superfamily.

Dowton \& Austin (1994) and Dowton et al. (1997) claim that apocritan wasp phylogenies based on morphology are hindered by problems associated with reductional synapomorphies because of the extremely small size of many members of this group. This should not be a problem when using spermatozoal ultrastructure as a basis for phylogenetic relationships, since the spermatozoan's size and consequently its ultrastructural characteristics are independent of wasp body size. In parasitic wasps, the longest spermatozoa are found in species of the superfamilies that constitute the socalled microhymenoptera (Proctotrupomorpha sensu Rasnitsyn 1988). For example, in the chalcidoid Bephratelloides pomorum, the spermatozoa measure $620 \mu \mathrm{m}$ in length, these being the largest spermatozoa so far observed in Hymenoptera (Lino-Neto et al. 1999). However, very little is yet known about the spermatozoal ultrastructure in the hymenopterans compared with other insect orders (Jamieson et al. 1999). While the spermatozoal ultrastructures of a few species pertaining to five of the six Symphyta families have been described (Quicke et al. 1992; Newman \& Quicke 1999a), this information is known for only six of the approximately 16 apocritan superfamilies, and some descriptions do not show sufficient detail to establish comparisons. Platygastroidea is one of the superfamilies whose spermatozoa have not yet been described; therefore, this is the first study of representatives of this taxon, which may shed new light on the evolutionary relationships between the parasitic wasps and, possibly, hymenopterans in general.

\section{Materials and methods}

Adult virgin males of Trissolcus basalis and Telenomus podisi were obtained from colonies maintained at the National Center for Genetic Resources of the Empresa Brasileira de Pesquisa Agropecuária (EMBRAPA), an institution for agricultural research, in Brasília, Brazil.

\section{Light microscopy}

The vas deferens was dissected and broken open on a clean glass microscope slide, where the sperm were spread and fixed in a solution of $4 \%$ paraformaldehyde in $0.1 \mathrm{M}$ phosphate buffer, $\mathrm{pH}$ 7.2. After drying at room temperature, the preparation was observed with an Olympus photomicroscope BX60 (Olympus Optical Co., Japan), equipped with phase contrast. To measure the nucleus, some of the preparations were stained for $15 \mathrm{~min}$ with $0.2 \mu \mathrm{g} / \mathrm{mL}$ 4,6-diamino-2-phenylindole (DAPI) in phosphate-buffered saline (PBS), washed and mounted with Vectashield. They were examined with an epifluorescence microscope (Olympus BX60), equipped with a BP360$370 \mathrm{~nm}$ excitation filter.

\section{Scanning electron microscopy}

Spermatozoa from the vas deferens were spread on a glass cover slip, fixed in $2.5 \%$ glutaraldehyde, dehydrated in acetone, critical point dried and sputter coated with gold. They were observed with a scanning electron microscope, JEOL JSM5800LV.

\section{Transmission electron microscopy}

Vasa deferentia were fixed for $2-4 \mathrm{~h}$ in a solution containing $2.5 \%$ glutaraldehyde, $3 \%$ sucrose, $0.2 \%$ picric acid in $0.1 \mathrm{M}$ cacodylate buffer at $\mathrm{pH}$ 7.2. After rinsing in buffer, they were post-fixed with $1 \%$ osmium tetroxide in the same buffer for 1-2 h. Dehydration was carried out in acetone and embedding in Epon 812 resin. Ultrathin sections, stained with uranyl acetate and lead citrate, were observed by transmission electron microscopy (Zeiss, Leo 906), operating at 40 and $80 \mathrm{kV}$.

\section{Results}

The spermatozoa of Trissolcus basalis and Telenomus podisi are slender and long, measuring about $100 \mu \mathrm{m}$ and $170 \mu \mathrm{m}$ in length, respectively (Figs 1A, 2A). In T. basalis, the acrosome is very small, measuring about $0.4 \mu \mathrm{m}$ in length, and is formed by an acrosomal vesicle and a perforatorium, which extends into the nucleus for approximately $0.5 \mu \mathrm{m}$ (Fig. 1C-E). No acrosome was observed in T. podisi, in spite of various spermatozoa having been observed sectioned in the anterior head region (arrows in Fig. 2C; Fig. 2E,F).

The nucleus, when stained with DAPI, is seen to be helicoidal (Figs 1B, 2B). In longitudinal sections as well as in scanning electron micrographs, it can be seen to coil around the single mitochondrial derivative (Figs $1 \mathrm{H}, \mathrm{J}, 2 \mathrm{~K}, \mathrm{M}$ ). In T. basalis, the nuclear tip extends beyond the mitochondrial derivative (arrowheads in Fig. 1D-F). The nucleus is about $25 \mu \mathrm{m}$ in length and the diameter is more or less constant, measuring approximately $160 \mathrm{~nm}$ at the base and $110 \mathrm{~nm}$ at the anterior tip (Fig. 1B-F). Where it runs in contact with the mitochondrial derivative, it is more or less triangular in cross-section (Fig. 1D,F). However, at its base, cross-sections show a crescent shape (Fig. 1I) and, at the anterior extremity, above the mitochondrial derivative, the nucleus assumes a pear shape (arrowheads in Fig. 1D-F). In T. podisi, the nucleus terminates shortly below the mitochondrial derivative tip (arrows in Fig. 2C,E). It is about $45 \mu \mathrm{m}$ in length, gradually tapers anteriorly from the base, where it measures approximately $240 \mathrm{~nm}$ (Fig. 2B,C,F,H). Differing from T. basalis, in this species the nucleus always presents a circular shape in crosssection (Fig. 2C,G,H). In both species, it is completely filled with homogeneous, compact chromatin (Figs 1B-F,H-L, 

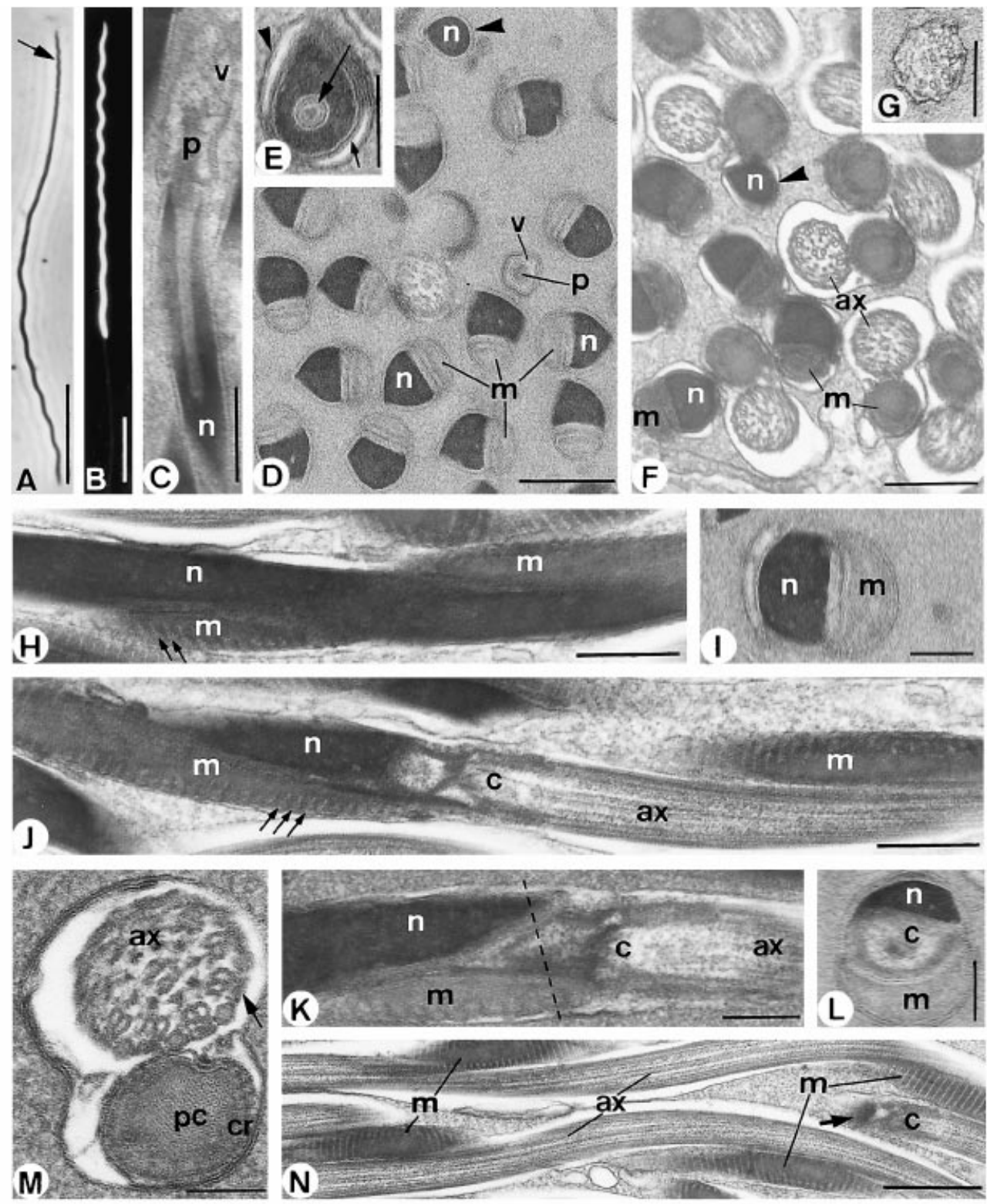

Fig. 1 Light micrographs (A,B) and transmission electron micrographs (C-N) showing morphological features of the spermatozoa of Trissolcus basalis. - A. Phase contrast of a spermatozoon. The arrow indicates the head region. - B. DAPI-stained fluorescence of the helicoidal nucleus. - C. Longitudinal section of the acrosomal region showing the acrosomal vesicle (v) and the perforatorium (p). $-\mathrm{D}$. Cross-sections of spermatozoa in the head region. Observe an acrosome $(\mathrm{v}, \mathrm{p})$ and the nucleus $(\mathrm{n})$ juxtaposed to the mitochondrial derivative $(\mathrm{m})$. The arrowhead indicates a nucleus sectioned beyond the mitochondrial derivative and below the acrosome. - E. Cross-section of a nuclear tip in which the perforatorium fits (larger arrow). The smaller arrow indicates the nuclear membrane, and the arrowhead the cell membrane. $-\mathrm{F}$. Crosssection of spermatozoa at different levels. Notice that the mitochondrial derivative is circular in the flagellar region and crescent shaped when juxtaposed with the nucleus. The arrowhead indicates a nucleus sectioned beyond the mitochondrial derivative. - G. Cross-section of an axoneme below the mitochondrial derivative. - H. Longitudinal section of a nuclear region. The arrows indicate the mitochondrial cristae. - I. Cross-section in the nuclear base. Observe that both the mitochondrial derivative and the nucleus are crescent shaped in this region. - J,K. Longitudinal sections of the nucleus-flagellum transition region. Notice the perfect fitting of the axonemal tip (c) in the nuclear wedge-shaped base. Arrows indicate the mitochondrial cristae. - L. Cross-section of the nucleus-flagellum transition region, probably positioned as indicated by the broken line in the previous figure. $-M$. Cross-section of a flagellum showing the twisted axoneme (ax) with the typical $9+9+2$ arrangement of microtubules, the intertubular material (arrow) and the mitochondrial derivative, consisting basically of cristae (cr) and a paracrystalline region $(\mathrm{pc})$. $-\mathrm{N}$. Longitudinal section of flagella. The arrow indicates the posterior nuclear tip. Scale bars: $\mathrm{A}=20 \mu \mathrm{m}$; $\mathrm{B}=5 \mu \mathrm{m} ; \mathrm{C}, \mathrm{G}, \mathrm{K}=0.2 \mu \mathrm{m} ; \mathrm{D}, \mathrm{F}, \mathrm{H}, \mathrm{J}=0.3 \mu \mathrm{m} ; \mathrm{E}, \mathrm{I}, \mathrm{L}, \mathrm{M}=0.1 \mu \mathrm{m} ; \mathrm{N}=0.5 \mu \mathrm{m}$. 


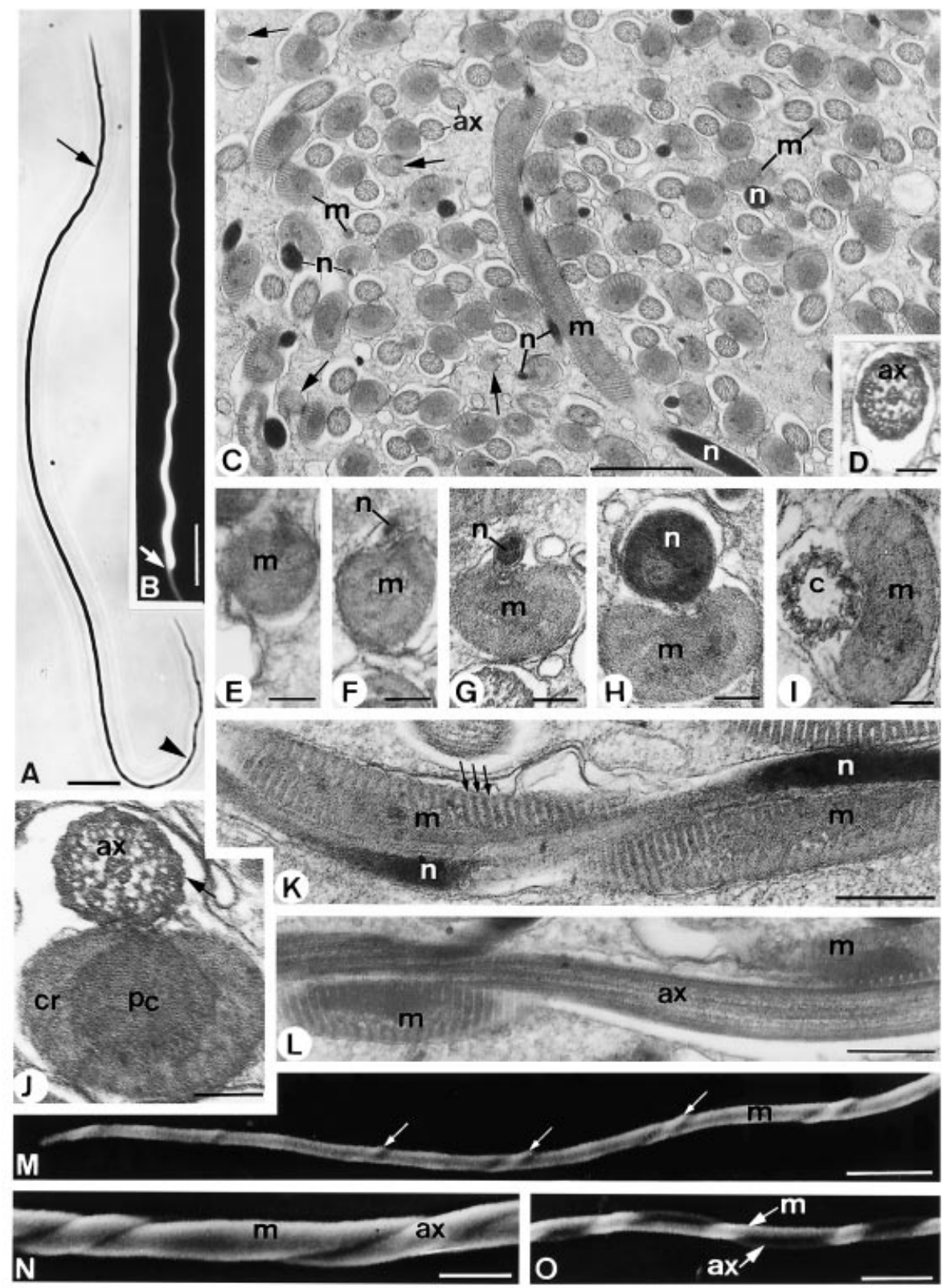

Fig. 2 Light micrographs (A,B) and transmission (C-L) and scanning (M-O) electron micrographs showing various features of the spermatozoa of Telenomus podisi. - A. Phase contrast of a spermatozoon showing the head region (arrow) and the posterior flagellar extremity (arrowhead). -B. DAPI-stained fluorescence of the helicoidal nucleus. The arrow indicates the nuclear base. —C. Micrograph showing various spermatozoa cross-sectioned at different levels. The arrows indicate mitochondrial derivatives $(\mathrm{m})$ sectioned above the nucleus (n). - D. Crosssection of an axoneme (ax) below the mitochondrial derivative. - E-H. Spermatozoan heads cross-sectioned either above the nucleus (E), at the anterior $(\mathrm{F}, \mathrm{G})$ or posterior $(\mathrm{H})$ nuclear extremities. - I. Flagellum cross-sectioned at the centriole (c). - J. Cross-section of a flagellum showing the axoneme (ax) with the typical $9+9+2$ arrangement of microtubules, the intertubular material (arrow) and the mitochondrial derivative, consisting basically of cristae (cr) and a paracrystalline region (pc). - K,L. Longitudinal sections of the head and flagellum regions, respectively. Arrows indicate the mitochondrial cristae. - M-O. Scanning electron micrographs showing the mitochondrial derivative coiling around the nucleus (arrows in $\mathrm{M}$ ) and the axoneme (N,O). Observe the different pattern between the anterior $(\mathrm{M})$ and posterior $(\mathrm{O})$ extremities, as seen with light microscopy (A). Scale bars: $\mathrm{A}=10 \mu \mathrm{m} ; \mathrm{B}=5 \mu \mathrm{m} ; \mathrm{C}, \mathrm{N}=1 \mu \mathrm{m} ; \mathrm{D}-\mathrm{J}=0.1 \mu \mathrm{m} ; \mathrm{K}, \mathrm{L}=0.3 \mu \mathrm{m} ; \mathrm{M}, \mathrm{O}=2 \mu \mathrm{m}$. 
2B, C, G,H,K) and, posteriorly, it is cut off and directly attached to the axoneme. No centriolar adjunct, as found in other hymenopterans, was observed in the nucleus-flagellum transition region (Figs 1J-L, 2I).

The flagellum is formed by the axoneme and the single mitochondrial derivative. It was not possible to clearly distinguish the presence of accessory bodies (Figs 1F,J,M,N, 2C,I,J,L,N,O). The axoneme, in the $9+9+2$ microtubule arrangement, has nine outer single accessory tubules surrounding nine doublets and two central single microtubules, as well as intertubular material (Figs 1F,M, 2J). In transverse sections, a spiral twisting of the microtubules is clearly observed, being more tightly twisted in T. basalis, since not all of the doublets can be sectioned at perfect right angles (Fig. 1F,M). In longitudinal sections as well as in scanning electron micrographs, the axoneme can be seen exhibiting a regular coil around the mitochondrial derivative (Figs $1 \mathrm{~N}, 2 \mathrm{~L}, \mathrm{~N}, \mathrm{O}$ ). The anterior axonemal tip fits perfectly into the wedge-shaped nuclear base (Fig. 1J,K). In T. basalis, the mitochondrial derivative begins shortly below the acrosome at the nuclear tip (arrowheads in Fig. 1D-F) and terminates just above the posterior axoneme tip (Fig. 1G). In cross-section, it is circular in the flagellar region and has a diameter approximately equal to the axoneme (Fig. 1F,M). Where it runs together with the nucleus, it assumes an approximately crescent shape (Fig. 1D,I,L). In T. podisi, the mitochondrial derivative begins above the nuclear tip (arrows in Fig. 2C,E,F), and its more or less oval crosssection is maintained along the entire spermatozoon. In the region of largest diameter, it attains approximately twice or more the diameter of the axoneme in cross-section (Fig. 2C,E-J). In the nucleus-flagellum transition region it is more or less concave, with the nucleus or axoneme (centriole) fitting its cavity (Fig. 2H,I). Here, the cross-section of the mitochondrial derivative measures almost twice the diameter of the nucleus (Fig. 2H). This proportion is not maintained since its diameter diminishes more slowly as the nucleus tapers off at the anterior tip (Fig. 2F,G). In both species, the mitochondrial derivative coils around the nucleus and axoneme (Figs $1 \mathrm{~N}, 2 \mathrm{~L}, \mathrm{~N}, \mathrm{O}$ ), and terminates just above the axoneme tip (Figs 1G, 2D). In cross-section, it is divided into two regions: a well-developed paracrystalline core surrounded by the mitochondrial cristae (Figs 1M, 2J,L). Longitudinal sections show that the cristae are parallel, with a periodicity of about $40 \mathrm{~nm}$ in T. basalis and $33 \mathrm{~nm}$ in T.podisi (Figs 1N, 2L).

\section{Discussion}

The spermatozoa of T. basalis and T. podisi present some ultrastructural characteristics which have not yet been observed in other Hymenoptera. Of these, the most notable is the presence of a single mitochondrial derivative, since the presence of two mitochondrial derivatives in the sperm of hymenopterans is considered standard. Two derivatives were observed in all the species already studied; therefore this is a derived characteristic and certainly very important for phylogenetic and taxonomic studies of this group. Also, the extension of the mitochondrial derivative, twisting around the nucleus up to its anterior end, as occurs in T. podisi, has not yet been observed in other hymenopterans. To date, the proctotrupoid, Psilus fuscipennis (Diapriidae), is the only hymenopteran in which one of the mitochondrial derivatives overlays the nucleus (Quicke et al. 1992). However, in this species, as in T. basalis, the derivative terminates below the nuclear tip. The compacted form of nucleus and derivative in cross-section is another similarity between $T$. basalis and P. fuscipennis (see fig. 6e in Quicke et al. 1992).

With regard to nuclear spiralling, to date, it has only been clearly demonstrated in chalcidoids (Lee \& Wilkes 1965; Hogge \& King 1975; Quicke 1997; Lino-Neto et al. 1999, 2000a). However, in these, no mitochondrial derivative overlays the nucleus. In the cynipoid, Leptopilina heterotoma, the spermatozoa present a nucleus with a posteriorly directed ridge, spiralling down along its surface (Newman \& Quicke 1999b). Although this can be considered a spiralling sperm form, we doubt if this 'spiralling' can be considered homologous to the nuclear spiralling that occurs in the chalcidoids and in the two species studied here. In these species, the nuclear axis follows a spiralling course while, in the cynipoid, the nuclear axis appears to be twisted and therefore its nuclear projection shows a spiralling course.

The acrosome in T. basalis can be considered to be the 'simple type', basically formed by an acrosomal vesicle and a perforatorium. Acrosomes with only these structures were also observed in the siricoid, Tremex sp. (Symphyta) (Newman \& Quicke 1999a), in ants (Wheeler et al. 1990) and in bees (J. Lino-Neto \& H. Dolder, personal observation 1999). However, in most of the apocritan wasps already examined, there is an extracellular sheath completely covering the acrosome and the anterior nuclear tip (see Quicke et al. 1992; Newman \& Quicke 1999b). Also, in the chalcidoids, numerous filaments radiate from this sheath (Lino-Neto et al. 1999, 2000a).

We recognize the difficulty of affirming that a structure does not exist because it has not been observed with electron microscopy. However, in T. podisi, based on the several sections at different levels of the spermatozoan's anterior end (see arrows in Fig. 2C and Fig. 2E-G), we are convinced that there really is no acrosome. For example, in this species, it is possible to observe the nuclear tip reduced to about $30 \mathrm{~nm}$ in diameter (approximately the same diameter as that of the perforatorium of T. basalis). As the perforatorium's diameter usually measures about one-third of the nuclear diameter in this region, if T. podisi had an acrosome and a perforatorium, this structure could not be more than $10 \mathrm{~nm}$ in diameter. None of the hymenopterans in which the acrosome has been described in detail present a perforatorium with such a small diameter. 
In most insects, there is usually an electron dense structure which surrounds, often asymmetrically, the bases of the mitochondrial derivatives and the axoneme where these attach to the posterior end of the nucleus (Jamieson et al. 1999). This structure is called the centriolar adjunct and in the mature spermatozoa of hymenopterans has only recently been identified (Wheeler et al. 1990; Newman \& Quicke 1998, 1999a,b; Lino-Neto et al. 1999, 2000a,b). Based on the hymenopterans in which it has been described, the centriolar adjunct can be classified morphologically into three types. The first type is more or less cylindrical and located between the nuclear base and the anterior tip of only one of the mitochondrial derivatives. The anterior tip of the other mitochondrial derivative is either in contact with the nuclear base (e.g. in Cephalcia, Newman \& Quicke 1999a) or lies beside the nucleus in a basolateral position (e.g. in Apis, Lino-Neto et al. 2000b). This type has already been identified in Ichneumonoidea (Newman \& Quicke 1998), Symphyta, except Siricoidea (Newman \& Quicke 1999a), Cynipoidea (Newman \& Quicke 1999b) and Apoidea (Lino-Neto et al. 2000b). In cross-sections of this region in the spermatozoa of these groups, the axoneme, one mitochondrial derivative and the centriolar adjunct are always observed together. This type is apparently the most common, being present, probably, in most bees and wasps. However, initially it was misinterpreted as being one of the mitochondrial derivatives (Quicke et al. 1992) or the nucleus (Chauvin et al. 1988). The second type differs from the first by its location between the nuclear base and both mitochondrial derivatives. This type has been observed in Siricoidea (Newman \& Quicke 1999a) and Formicidae (Wheeler et al. 1990). Initially, this type was misinterpreted as being an extension of the nucleus overlying the axoneme. The third type to date has been observed only in chalcidoids, where it reaches partially around the basolateral nuclear region and the axoneme tip. In this type, the two mitochondrial derivatives touch the adjunct's posterior extremity (Lino-Neto et al. 1999, 2000a). Cross-sections shortly below the nucleus show only the axoneme and the centriolar adjunct in spermatozoa of those species that present the second and third types.

Probably, the early misinterpretations cited above occurred because the structure and location of the centriolar adjunct in hymenopterans differ widely from that in other insects (see Jamieson et al. 1999) and, due to these misinterpretations, this structure was believed, until recently, to be absent in the Hymenoptera. However, considering recent publications, it seems probable that the centriolar adjunct is present in practically all Hymenoptera. Therefore, since this structure, as described in other hymenopterans, does not exist in Scelionidae, this may be an important characteristic to be used in phylogenetic studies of parasitic wasps.

The presence of a single mitochondrial derivative in scelionids differentiates this family, as well as the superfamily
Platygastroidea, should platygastrids also possess only one derivative, from all the other hymenopteran groups already studied. The basic type of hymenopteran spermatozoon presents a flagellum consisting of an axoneme, two mitochondrial derivatives and two accessory bodies (Jamieson et al. 1999). As regards the coiling of the mitochondrial derivatives around the twisted axoneme, this has been described in detail only in chalcidoids (Lee \& Wilkes 1965; Wilkes \& Lee 1965; Hogge \& King 1975; Quicke et al. 1992; Lino-Neto et al. 1999, 2000a). However, this group presents two mitochondrial derivatives which have a very small diameter and are closely adpressed to the axoneme. In the chalcidoids, the derivatives begin in contact with the posterior extremity of the centriolar adjunct, a short distance from the nuclear base (Lino-Neto et al. 1999, 2000a). Quicke et al. (1992) described that, besides the chalcidoids, the spermatozoan spiralling was 'not found in any other superfamily apart from a weak indication in the Diapriidae.' However, this arrangement in these wasps was confirmed recently by D. L. J. Quicke (personal communication 2000).

Rasnitsyn (1988) proposed four major lineages within the suborder Apocrita: the Ichneumonomorpha, the Vespomorpha (Aculeata), the Evaniomorpha and the Proctotrupomorpha. Also, according to this author, the latter lineage contains the Cynipoidea, Proctotrupoidea, Chalcidoidea and Platygastroidea. However, analyses based on molecular data placed the Cynipoidea as a relatively basal apocritan lineage (Dowton et al. 1997). These same analyses also supported the inclusion of this superfamily within the Evaniomorpha rather than within the Proctotrupomorpha. On the other hand, it supported the inclusion of the Platygastroidea (Scelionidae and Platygastridae) and Chalcidoidea within the Proctotrupomorpha, and suggested that they were more closely related to the Diapriidae (Proctotrupoidea) than to any other family included in the Proctotrupomorpha (Dowton et al. 1997). This proposal agrees with Rasnitsyn (1980) (Diapriidae closely related to Platygastroidea) and Rasnitsyn (1988) (Chalcidoidea closely related to Platygastroidea). Gibson (1999) suggested, based on morphological data, that the Chalcidoidea are a relatively early clade within Apocrita and that this superfamily is, possibly, more closely related to Diapriidae. This author also proposed that 'Platygastroidea forms a monophyletic lineage with Pelecinidae, Proctotrupidae and Vanhorniidae, as with Chalcidoidea'.

Based on the data presented above, we can observe that the ultrastructures of the spermatozoa of those species of Proctotrupomorpha (sensu Rasnitsyn 1988) already studied have elements in common, which would lead to a grouping according to that suggested by most of the phylogenetic studies based on morphological and molecular data (Rasnitsyn 1988; Dowton \& Austin 1994; Dowton et al. 1997). For example, the helicoidal nucleus and the mitochondrial derivatives coiling around the twisted axoneme in Platygastroidea 
(Scelionidae) suggest that it is closely related to Chalcidoidea. Likewise, the mitochondrial derivative running together with the nucleus for a long distance suggests that it is also closely related to Diapriidae (Quicke et al. 1992). If, in fact, Diapriidae presents spiralling spermatozoa, this would suggest that this family is as closely related to Platygastroidea as to Chalcidoidea. Two characters suggest that the cynipoids are not closely related to the scelionids and chalcidoids. The first is the lack of a spiralling structure in the flagellar elements of Figites sp. (Quicke et al. 1992) and L. heterotoma (Newman \& Quicke 1999b). The second is the fact that there is no homology between the type of 'nuclear spiralling' present in spermatozoa of L. heterotoma and that of scelionids and chalcidoids.

Also, the spermatozoa of these cynipoids present a centriolar adjunct located between the nuclear base and one of the mitochondrial derivatives (Newman \& Quicke 1999b) which differentiate them from those of Chalcidoidea and Scelionidae. All these characteristics appear to agree with the phylogenetic analyses presented by Dowton et al. (1997) when the inclusion of this superfamily is considered within other lineages (Evaniomorpha) rather than within the Proctotrupomorpha.

According to Dowton et al. (1997), there is still little consensus between the several phylogenetic hypotheses for the Proctotrupomorpha. This is likely to be resolved only by the combined analysis of molecular and morphological data, including newly described character systems. Therefore, we are more and more convinced that, in the hymenopterans, or at least in the parasitic wasps, the structural diversity of the spermatozoa will be sufficient to furnish a character system which could be used, associated with other systems, to resolve some of the uncertainties about the evolutionary relationships of this important insect group.

\section{Acknowledgements}

We would like to thank A. P. Fernandes for helping us to contact Dr M. Borges (National Center for Genetic Resources of the EMBRAPA, in Brasília, Brazil) who supplied the insects and S. N. Báo for critical reading of the manuscript. This research was supported by Brazilian research grants from CAPES and FAPESP.

\section{References}

Baccetti, B. (1972). Insects sperm cells. Advances in Insects Physiology, 9, 315-397.

Carcupino, M., Profili, G., Kathirithamby, J. \& Mazzini, M. (1995). Sperm ultrastructure of Xenos vesparum (Rossi) and its significance in the taxonomy and phylogeny of Strepsiptera (Insecta). Mémoires du Muséum National d'Histoire Naturelle, 166, 291-296.

Chauvin, G., El Agoze, M., Hamon, C. \& Huignard, J. (1988). Ultrastructure des spermatozoïdes des males haploïdes et diploïdes de Diadromus pulchellus Wesmeal (Hymenoptera: Ichneumonidae). International fournal of Insect Morphology and Embryology, 17, 359-366.
Dallai, R. (1979). An overview of atypical spermatozoa in insects. In W. Fawcett \& J. M. Bedford (Eds) The Spermatozoon (pp. 253-256). Baltimore: Urban and Schwarzenberg.

Dallai, R. \& Afzelius, B. A. (1990). Microtubular diversity in insect spermatozoa: results obtained with a new fixative. Fournal of Structural Biology, 103, 164-179.

Dallai, R. \& Afzelius, B. A. (1995). Phylogenetic significance of axonemal ultrastructrure: examples from Diptera and Trichoptera. Mémoires du Muséum National d'Histoire Naturelle, 166, 301-310.

Dowton, M. \& Austin, A. D. (1994). Molecular phylogeny of the insect order Hymenoptera: apocritan relationships. Proceedings of the National Academy of Sciences of the USA, 91, 9911-9915.

Dowton, M., Austin, A. D., Dillon, N. \& Bartowsky, E. (1997). Molecular phylogeny of the apocritan wasps: the Proctotrupomorpha and Evaniomorpha. Systematic Entomology, 22, 245-255.

Gaston, K. J. (1991). The magnitude of global insect species richness. Conservation Biology, 5, 283-296.

Gauld, I. D. \& Bolton, B. (1988). The Hymenoptera. Oxford: Oxford University Press.

Gauld, I. D. \& Hanson, P. E. (1995). The evolution, classification and identification of the Hymenoptera. In P. E. Hanson \& I. D. Gauld (Eds) The Hymenoptera of Costa Rica (pp. 138-156). New York: Oxford University Press.

Gibson, G. A. P. (1999). Sister-group relationships of the Platygastroidea and Chalcidoidea (Hymenoptera) - an alternative hypothesis to Rasnitsyn (1988). Zoologica Scripta, 28, 125-138.

Hanson, P. E. (1995). Economic importance of Hymenoptera. In P. E. Hanson \& I. D. Gauld (Eds) The Hymenoptera of Costa Rica (pp. 89-100). New York: Oxford University Press.

Hogge, M. A. F. \& King, P. E. (1975). The ultrastructure of spermatogenesis in Nasonia vitripennis (Walker) (Hymenoptera: Pteromalidae). Fournal of Submicroscopic Cytology, 7, 81-96.

Jamieson, B. G. M., Dallai, R. \& Afzelius, B. A. (1999). Insects: Their Spermatozoa and Phylogeny. Enfield, New Hampshire: Science Publishers, Inc.

Königsmann, E. (1978). Das phylogenetische System der Hymenoptera. Teil 3. Terebrantes (Unterordnung Apocrita). Deutsche Entomologische Zeitschrift, 25, 1-55.

Lee, P. E. \& Wilkes, A. (1965). Polymorphic spermatozoa in the hymenopterous wasp Dablbominus. Science, 147, 1445-1446.

Lino-Neto, J., Báo, S. N. \& Dolder, H. (1999). Structure and ultrastructure of the spermatozoa of Bephratelloides pomorum (Fabricius) (Hymenoptera: Eurytomidae). International fournal of Insect Morphology and Embryology, 28, 253-259.

Lino-Neto, J., Báo, S. N. \& Dolder, H. (2000a). Structure and ultrastructure of the spermatozoa of Trichogramma pretiosum Riley and Trichogramma atopovirilia Oatman and Platner (Hymenoptera: Trichogrammatidae). Acta Zoologica, 81, 205-211.

Lino-Neto, J., Báo, S. N. \& Dolder, H. (2000b). Sperm ultrastructure of the honey bee (Apis mellifera) (L.) (Hymenoptera, Apidae) with emphasis on the nucleus-flagellum transition region. Tissue and Cell, 32, 322-327.

Masner, L. (1993). Superfamily Platygastroidea. In H. Goulet \& J. T. Huber (Eds) Hymenoptera of the World: an Identification Guide to Families (pp. 558-565). Ottawa: Research Branch, Agriculture Canada.

Masner, L. (1995). The proctotrupoid families. In P. E. Hanson \& I. D. Gauld (Eds) The Hymenoptera of Costa Rica (pp. 209-246). New York: Oxford University Press. 
Ultrastructural characteristics of Scelionidae sperm • 7. Lino-Neto \& H. Dolder

Newman, T. M. \& Quicke, D. L. J. (1998). Sperm development in the imaginal testes of Aleiodes coxalis (Hymenoptera: Braconidae: Rogadinae). Fournal of Hymenoptera Research, 7, 25-37.

Newman, T. M. \& Quicke, D. L. J. (1999a). Ultrastructure of imaginal spermatozoa of sawflies (Hymenoptera: Symphyta). Journal of Hymenoptera Research, 8, 35-47.

Newman, T. M. \& Quicke, D. L. J. (1999b). Ultrastructure of Spermatozoa in Leptopilina (Hymenoptera: Cynipoidea: Eucoilidae). Journal of Hymenoptera Research, 8, 197-203.

Quicke, D. L. J. (1997). Preimaginal development: from gametogenesis to syngamy. In: D. L. J. Quicke (Ed.) Parasitic Wasps (pp. 79101). London: Chapman \& Hall.

Quicke, D. L. J., Ingram, S. N., Baillie, H. S. \& Gaitens, P. V. (1992). Sperm structure and ultrastructure in the Hymenoptera (Insecta). Zoologica Scripta, 21, 381-402.
Rasnitsyn, A. P. (1980). The origin and evolution of the Hymenoptera. Trudy Paleontologicheskogo Instituta Akademiya Nauk SSSR, 174, 1-192 (in Russian).

Rasnitsyn, A. P. (1988). An outline of evolution of the hymenopterous insects (Order Vespida). Oriental Insects, 22, 115-145.

Ronquist, F., Rasnitsyn, A. P., Roy, A., Eriksson, K. \& Lindgren, M. (1999). Phylogeny of the Hymenoptera: a cladistic reanalysis of Rasnitsyn's (1988) data. Zoologica Scripta, 28, 13-50.

Wheeler, D. E., Crichton, E. G. \& Krutzsch, P. H. (1990). Comparative ultrastructure of ant spermatozoa (Formicidae: Hymenoptera). Fournal of Morphology, 206, 343-350.

Wilkes, A. \& Lee, P. E. (1965). The ultrastructure of dimorphic spermatozoa in hymenopteran Dablbominus fuscipennis (Zett.) (Eulophidae). Canadian Fournal of Genetics and Cytology, 7, 609-619. 
Copyright of Zoologica Scripta is the property of Wiley-Blackwell and its content may not be copied or emailed to multiple sites or posted to a listserv without the copyright holder's express written permission. However, users may print, download, or email articles for individual use. 